

\section{A BRINQUEDOTECA E A FORMAÇ̃̃O DO PEDAGOGO: BREVES APONTAMENTOS}

\section{THE TOY LIBRARY AND TRAINING OF PEDAGOGUE: BRIEF POINTS}

\section{LA LUDOTECA Y LA FORMACIÓN DE PEDAGOGO: BREVES PUNTOS}

Tatiana Platzer do Amaral ${ }^{1}$ Celia Regina da Silva ${ }^{2}$ Renan Antônio da Silva ${ }^{3}$ Ana Paula Torres Perez ${ }^{4}$ Douglas Gustavo Prado ${ }^{5}$

\section{RESUMO}

O presente artigo tem como proposta realizar apontamentos sobre a brinquedoteca, enquanto laboratório didático, na formação do pedagogo. Sobre a brinquedoteca e as políticas públicas em educação para formação do pedagogo destaca-se que os documentos oficiais, como diretrizes curriculares e instrumentos de avaliação de curso, apresentam informações superficiais sobre a função da brinquedoteca. Para se construir uma proposta de brinquedoteca universitária, minimamente, comprometida é preciso analisar os documentos oficiais que embasam as práticas na Educação Infantil a fim de se compreender a concepção de infância. Aliada a essa questão verificou-se a ausência de referência ou classificação dos tipos de brinquedoteca, bem como de uma concepção comum. A partir dos dados da pesquisa apresentada foi reforçada a ideia de que a relação entre brinquedoteca e formação do pedagogo ainda está em processo de construção. Finalizando, as contribuições da Psicologia Histórico-Cultural evidenciam a importância da brincadeira para desenvolvimento como atividade central no processo de formação do psiquismo infantil.

\section{PALAVRAS-CHAVE}

Brinquedoteca. Formação Pedagogo. Educação Infantil. 
This article aims to make notes on the playroom, as a didactic laboratory, in the education of the pedagogue. About the playroom and the public policies in education for the education of the pedagogue, it is noteworthy that the official documents, such as curricular guidelines and course evaluation instruments, present superficial information about the role of the playroom. In order to construct a minimally compromised proposal for a university playroom/toy library, it is necessary to analyze the official documents that support the practices in early childhood education in order to understand the conception of childhood. Allied to this issue was the absence of reference or classification of types of playroom, as well as a common conception. From the data of the research presented, the idea that the relationship between toy library and teacher education is still under construction is reinforced. Finally, the contributions of Historical-Cultural Psychology highlight the importance of play for development as a central activity in the process of formation of the child psyche.

\section{KEYWORDS}

Toy Library. Pedagogical Training. Early Childhood Education.

\section{RESUMEN}

Este artículo tiene como objetivo tomar notas sobre la ludoteca, como laboratorio didáctico, en la educación del pedagogo. Sobre la sala de juegos y las políticas públicas en educación en la capacitación del pedagogo, cabe destacar que los documentos oficiales, como las directrices curriculares y los instrumentos de evaluación de cursos, presentan información superficial sobre el papel de la sala de juegos. Para construir una propuesta mínimamente comprometida para una ludoteca universitaria, es necesario analizar los documentos oficiales que respaldan las prácticas en la educación de la primera infancia para comprender la concepción de la infancia. Aliado a esta pregunta estaba la ausencia de referencia o clasificación de los tipos de sala de juegos, así como una concepción común. A partir de los datos de la investigación presentada, se refuerza la idea de que la relación entre la ludoteca y la formación del profesorado aún está en construcción. Finalmente, los aportes de la psicología histórico-cultural destacan la importancia del juego para el desarrollo como actividad central en el proceso de formación de la psique infantil.

\section{PALABRAS CLAVE}

Ludoteca, Capacitación pedagógica, Educación de la primera infancia. 


\section{INTRODUÇ̧̃̃o}

O presente artigo tem como proposta realizar apontamentos sobre a brinquedoteca, enquanto laboratório didático, na formação do pedagogo. Incialmente busca-se a contextualização nas políticas públicas em educação voltadas para a formação do pedagogo da brinquedoteca, enquanto laboratório didático. Em um segundo momento, contextualiza-se historicamente o espaço denominado brinquedoteca.

Posteriormente, com base nos dados de pesquisa $\mathbf{A}$ brinquedoteca e a formação do pedagogo sob a perspectiva histórico-cultural, desenvolvida em 2017-2018 como parte do Programa de Iniciação Científica da Universidade de Mogi das Cruzes (UMC). Apresenta uma análise de publicações vinculadas ao tema brinquedoteca e formação do professor, em que se buscou identificar que relações se estabelecem entre a existência de brinquedotecas em universidades que oferecem o curso de graduação em pedagogia e a formação dos pedagogos.

\section{BRINQUEDOTECA E AS POLÍTICAS PÚBLICAS EM EDUCAÇÃO DE FORMAÇÃO DE PROFESSOR}

Em temos de políticas públicas em educação destaca-se a publicação da Resolução $\mathrm{CNE} / \mathrm{CP}$ n¹ - 2006 e da Resolução CNE/CP n² - 2015 que, enquanto diretrizes curriculares nacionais, enfatizam a formação do pedagogo voltada para atuação na Educação Básica (Educação Infantil e Ensino Fundamental - anos iniciais). Alinham-se à concepção de infância presente no Referencial Curricular Nacional para a Educação Infantil de 1998 que destaca a relação entre o cuidar e educar, bem como a importância do papel do brincar no desenvolvimento infantil.

No entanto, o entendimento e a exigência da brinquedoteca, enquanto um laboratório do curso de Pedagogia, apresenta-se como requisito nos instrumentos de avaliação de curso do Instituto Nacional de Estudos e Pesquisas Educacionais Anísio Teixeira (INEP). A primeira referência é como um laboratório de ensino no instrumento de avaliação de cursos superiores somente de Pedagogia de 2010. Nos instrumentos de 2012 e 2015 de avaliação de cursos de graduação presencial e a distância, licenciatura e bacharelado) passa a ser considerada como laboratório didático especializado da Pedagogia.

Já nos instrumentos de 2017, também de avaliação de cursos de graduação presencial e a distância, licenciatura e bacharelado, encontra-se no glossário a definição de laboratórios didáticos como recintos em que são desenvolvidas atividades pedagógicas que articulam teoria e prática. A nova denominação utilizada é de laboratórios didáticos de formação específica, ou seja, subentende-se que a brinquedoteca é um deles.

Diante da breve exposição, defende-se a brinquedoteca como um laboratório didático privilegiado para formação do pedagogo, por meio de atividades de ensino, pesquisa e extensão. A organização e funcionamento dela deve refletir uma concepção de desenvolvimento humano e infância que tem implicação direta nas práticas, de jogos e brincadeiras, a serem desenvolvidas, o que requer sólida formação teórica. 
O desenvolvimento de práticas reconhece a necessidade de reflexões sistemáticas e fundamentadas para seu aprimoramento e análise o que implica em uma postura investigativa, que fomenta a pesquisa. Todas as atividades desenvolvidas na brinquedoteca adotam o princípio de que, para além de ser uma sala de brinquedos, requer um posicionamento teórico diante do entendimento do processo educativo, referendado por uma concepção de desenvolvimento infantil e infância, que tem implicações nas práticas desenvolvidas.

\section{BRINQUEDOTECA E HISTÓRIA}

No que se refere a origem das brinquedotecas, de acordo com Porto (1998), a primeira brinquedoteca surge em 1934, em Los Angeles, com o intuito de diminuir as queixas de roubos de brinquedos. Juntamente forma-se o primeiro conceito de brinquedoteca em que ocorriam empréstimos de brinquedos para as crianças.

Posteriormente, em 1960, surgiu na Suécia uma ideia diferente de brinquedoteca, em que se tinha como objetivo, além do empréstimo de brinquedos, também orientar famílias de crianças com necessidades educativas especiais. Orientar a forma do brincar com objetivo de estimular o desenvolvimento das crianças. Concomitantemente, na Inglaterra surgiu a primeira brinquedoteca em bibliotecas (toy libraries) e as crianças podiam emprestar os brinquedos e levar para casa.

No Brasil, a primeira brinquedoteca foi criada em 1981, em uma escola municipal em São Paulo e tinha como objetivo estimular as crianças para brincarem livremente. Logo em seguida, em 1982, na cidade de Natal, uma professora da área de educação especial conseguiu junto à comunidade doações de brinquedos destinados a montagem de uma brinquedoteca.

Ainda segundo Porto (1998), outras iniciativas podem ser apontadas em que novas funções foram sendo atribuídas para o espaço do brincar, como por exemplo o projeto "Brinquedoteca Terapêutica", criado em 1986 por profissionais especializados que atuavam na Associação de Pais e Amigos dos Excepcionais (APAE). Destaca-se que contando com uma estrutura adequada tornou-se referência e contribuiu para a expansão dos ideais da brinquedoteca.

A primeira brinquedoteca universitária é de 1989 e foi criada em uma universidade do Sul do Brasil. É fruto de iniciativa financiada por fundação holandesa que visava o estudo do brincar, da criança e a educação. Reconhecendo a expansão e a diversidade de práticas, em 1992, a Fundação Abrinq fez um levantamento das brinquedotecas no Brasil e encontrou 36 unidades.

De maneira geral, pode-se afirmar que a brinquedoteca

É um espaço que valoriza as atividades lúdicas e criativas, possibilitando uma variedade de brinquedos, ela também estimula o desenvolvimento global das crianças e enriquece as relações familiares desenvolvendo hábitos de responsabilidade e trabalho, dando condições para que as crianças brinquem com espontaneidade, despertando o interesse por uma nova forma de animação cultural que pode diminuir a distância entre as gerações. (SILVÉRIO; RUBIO, 2012, p. 3). 
Parte-se da constatação de que não há uma classificação de referência para os tipos de brinquedoteca. Consultando diferentes autores serão escritos brevemente os tipos mais prevalentes na bibliografia consultada.

\subsection{BRINQUEDOTECAS COMUNITÁRIAS}

Organizadas em comunidades, geralmente, desprovidas de espaços de lazer, por organizações não governamentais ou alguém da própria localidade. Funcionam de diferentes formas: empréstimos de brinquedos, desenvolvem atividades lúdicas, oficinas dentre outros no próprio local. Os objetivos são:

[...] oferecer experiências que possam favorecer encontros entre pessoas da comunidade; capacitar membros da comunidade para que possam auxiliar a manter e dar continuidade ao projeto; favorecer atividades que ajudem o enriquecimento cultural e social entre os usuários; orientar os pais para que possam auxiliar o desenvolvimento de seus filhos; possibilitar à criança a exploração e o uso de diferentes materiais evitando o consumo; e, contribuir para o desenvolvimento da autonomia infantil.(CARNEIRO, 2015, p.3)

\subsection{BRINQUEDOTECA HOSPITALAR}

Organizadas em instituições hospitalares que atendem crianças e adolescentes. Geralmente há um espaço específico em que se disponibilizam brinquedos e jogos:

que podem ser levados ou não para os leitos dependendo das condições clínicas do paciente. Auxiliam na recuperação e amenizam trauma psicológico da hospitalização através atividades lúdicas. (SILVÉRIO e RUBIO, 2012, p. 26, apud KISHIMOTO, 1998)

\subsection{BRINQUEDOTECA DE SHOPPING, SUPERMERCADOS E GRANDES MAGAZINES}

Tem como finalidade oferecer um espaço com atividades, brinquedos e jogos variados para crianças enquanto os responsáveis fazem compras (SILVÉRIO; RUBIO, 2012, p. 8 apud KISHIMOTO, 1998).

\subsection{BRINQUEDOTECA EM CENTROS CULTURAIS}

Tem como finalidade, segundo Carneiro (2015), promover o intercâmbio cultural entre crianças, e demais usuários, além da competição e a colaboração entre os usuários, podendo promover concursos e de acordo com a proposta e acervo realizar empréstimo de brinquedos.

\subsection{BRINQUEDOTECA PARA CRIANÇAS COM DEFICIÊNCIA}

São brinquedotecas que se especializam na adaptação de brinquedos para atender alguma modalidade de deficiência motora, visual, auditiva ou intelectual. Nesses casos, há uma equipe especialistas 
que orientam as crianças e seus familiares. Tem como objetivo principal permitir à criança com deficiência o desenvolvimento e aprendizagem por meio de brinquedos e computadores (KISHIMOTO, 1992).

\subsection{BRINQUEDOTECAS EM CLÍNICAS PSICOLÓGICA, ODONTOLÓGICA E MÉDICA}

São espaços com caráter terapêutico, de acordo com a especificidade do tratamento. Possuem brinquedos e jogos, vinculados ou não com a área de atendimento (CARNEIRO,2015, p. 4).

\subsection{BRINQUEDOTECA ESCOLAR}

Estão inseridas em instituições escolares no apoio a atividades que favoreçam o desenvolvimento de crianças. É um espaço com objetos lúdicos e de materiais necessários às atividades pedagógicas e de lazer. Carneiro (2015) complementa os objetivos:

[...] oferecer um espaço de brincadeiras para que as crianças realizem suas próprias escolhas; permitir um ambiente de observação e de reflexão para que os profissionais conheçam melhor as crianças e ajudem a desenvolvê-las; estimular e favorecer as relações entre pais e filhos, educadores e crianças e entre as próprias crianças; cooperar com os pais orientando-os para a escolha de brinquedos e evitando o consumo exagerado; e, oferecer à criança o acesso à variedade de materiais. (CARNEIRO, 2015, p. 3).

\subsection{BRINQUEDOTECA UNIVERSITÁRIA}

Estão vinculadas a instituições de educação superior e tem como finalidade oportunizar a formação de profissionais que valorizem a brincadeira e sejam capazes de atuar em instituições educativas. A formação envolve o desenvolvimento de pesquisas, analisando a questão do lúdico no processo educativo e na prática da cidadania, promovendo a valorização da cultura da infância. Podem envolver o empréstimo de brinquedos e o desenvolvimento de atividades com crianças. (CARNEIRO, 2015).

Esta é uma proposta de classificação de brinquedotecas a partir da contribuição de diferentes autores, mas vale ressaltar que não há o intuito de esgotar as possibilidades.

\section{A PESQUISA}

Orientou-se pela finalidade de analisar as publicações vinculadas ao tema brinquedoteca, em que se buscou identificar que relações se estabelecem entre a existência de brinquedotecas em universidades que oferecem o curso de graduação em pedagogia e a formação dos pedagogos.

Caracterizou-se por uma perspectiva qualitativa, de cunho teórico envolveu a análise de produções acadêmico-cientificas disponíveis na plataforma Google acadêmico. A pesquisa foi realizada, delimitando o período a partir de 2016, por meio de palavras-chave, a saber, "brinquedoteca universitária e forma- 
ção de professores”. Após leitura e análise das produções encontradas foram selecionados apenas os que abordavam o tema de acordo com o objeto da pesquisa, possibilitando, assim, uma análise comparativa.

- REIS, Frankson Santiago; ARAÚJO, Patrícia do Socorro Chaves de; BAPTISTA, Tadeu João Ribeiro. Brinquedoteca universitária e formação de professores: [in]visibilidades acadêmicas. Dossiê Aspectos Históricos do Esporte e Lazer, Belo Horizonte, v. 3, n. 4, p.96-115, dez. 2017. Quadrimestral. Disponível em: https://seer.ufmg.br/index.php/rbel/article/view/10195.

- MENDES, Jacqueline Araujo Corrêa et al. Brinquedoteca Universitária: espaço de formação e de experiências lúdicas. Revista Intercâmbio, v. 11, p. 187-204, 2018. Disponível em: http://www. intercambio.unimontes.br/index.php/intercambio/article/view/76.

- KOCHEM, Kedma Silveira Barbosa Camargo; VALENTE, Filomena Mie; DE SOUZA MARCATO, Daniela Cristina Barros. A importância do projeto brinquedoteca aberta na Universidade Federal de Mato Grosso do Sul para formação pedagógica dos discentes. Campo Grande, v. 1, n. 1, 2018. Disponível em: http://anaisonline.uems.br/index.php/jornadaeducacao/article/view/4875/4902.

A análise comparativa foi orientada por alguns aspectos apontados por Bardin (2006 apud MOZZATO; GRZYBOVSKI, 2011) e utilizou um conjunto de técnicas de análise das comunicações, com procedimentos sistemáticos e objetivos de descrição do conteúdo das mensagens.

\subsection{RESULTADOS E DISCUSSÕES}

Para maior clareza e organização as publicações serão denominadas da seguinte forma:

- Publicação 1 - A importância do projeto Brinquedoteca aberta na Universidade Federal do Mato Grosso do Sul para a formação pedagógica dos discentes.

Objetivo: Mostrar a relevância da brinquedoteca para a formação do pedagogo.

- Publicação 2 - Brinquedoteca universitária e formação de professores: [In]visibilidade acadêmica Objetivo: Compreender quais contribuições a brinquedoteca universitária oferece enquanto espaço de formação de professores.

- Publicação 3 - Brinquedoteca universitária: espaço de formação e experiências lúdicas Objetivo: Refletir sobre as experiências de formação propiciadas pelo projeto "Brinquedoteca: espaço de interação sociocultural no contexto da universidade

A partir de análise comparativa das publicações selecionadas verificou-se que as principais semeIhanças com relação ao conteúdo abordado foram:

- Buscam compreender a importância da brinquedoteca enquanto a um espaço de formação dos professores;

- Propõem uma visão ampliada da prática pedagógica;

- Visam a articulação da teoria com a prática, isto é, oferecem aos acadêmicos a oportunidade de um espaço formativo de vínculo teoria e prática;

- Publicação 1 e 2 concebem, segundo Vigotski, as contribuições do brincar para o desenvolvimento das crianças; 
- Publicação 2 e 3 visam o brincar para aprender de modo que os professores usem em suas práticas pedagógicas e a brinquedoteca universitária tem um papel importante neste contexto formativo, por articular a teoria com a prática.

As principais diferenças observadas na análise do conteúdo dos trabalhos selecionados foram:

- Em relação ao enfoque a Publicação 1 analisa um projeto de brinquedoteca aberta caracterizada como uma atividade de extensão acadêmica, a Publicação 2 relata a análise da aplicação de um questionário aos acadêmicos de Pedagogia para saber a importância da brinquedoteca e a Publicação 3 analisa a influência de um projeto de extensão na formação dos professores;

- Na Publicação 2 a brinquedoteca é definida como uma nova instituição que nasceu neste século para garantir à criança um espaço destinado a facilitar o ato de brincar. É caracterizada por possuir um conjunto de brinquedos, jogos e brincadeiras. Afirma ser um ambiente agradável, alegre e colorido em que mais importante do que os brinquedos é a ludicidade proporcionada;

- A Publicação 1 defende que a brinquedoteca visa proporcionar o acesso a um conjunto de jogos e brincadeiras em uma perspectiva livre e espontânea, em relação às escolhas das crianças. Sendo importante deixá-las com uma compreensão de que a brincadeira deve ser coisa séria e orientada por regras que visam a socialização das crianças, a inclusão e a prática do respeito;

- Na Publicação 3 a brinquedoteca caracterizada como um espaço privilegiado para o desenvolvimento das crianças, bem como para a produção de conhecimento sobre a infância, favorecendo a linguagem lúdica das crianças, o desenvolvimento social, cognitivo e afetivo.

Em continuidade à análise comparativa e a discussão, com base na perspectiva da Psicologia Histórico-cultural sobre o brincar e o desenvolvimento infantil, é possível fazer alguns apontamentos. Parte-se da premissa de que segundo Vigotski (2001, apud ARCE, 2004), o desenvolvimento infantil é um processo dialético em que a passagem de uma fase para outra é marcada não pela simples evolução, mas por uma revolução que implica em mudanças qualitativas na vida da criança.

Ainda, com base na mesma autora, o brincar da criança não é meramente uma ação espontânea e livre, mas sim uma forma de se apropriar do mundo, o que se revela aspecto fundamental a ser trabalhado na formação dos professores, tendo em vista as implicações para o desenvolvimento do trabalho pedagógico.

Facci (2004), com base nas contribuições de Vigotski, afirma que a psique humana é compreendida como uma construção histórica em que o psiquismo humano se desenvolve por meio de uma mediação entre o sujeito e o objeto de sua atividade, de maneira que as funções psicológicas superiores são formadas em sua interação com o mundo, para além de explicações idealistas que priorizam a adaptação da criança ao meio.

Eidt e Duarte (2007), partindo de uma compreensão histórica sobre o desenvolvimento humano, situam a educação escolar como uma atividade mediadora na relação entre a criança e a sociedade e afirmam:

Para Leontiev (1967), a criança se encontra com um mundo criado e transformado pela atividade humana das gerações precedentes. Ela não pode simplesmente "estar" neste mundo, precisa viver e atuar sobre ele, usando instrumentos, o idioma e a lógica já elaborados pela sociedade, além de não permanecer indiferente às criações artísticas. Ele 
evidencia que a criança não possui “aptidões preparadas de antemão" para realizar essas tarefas, como, por exemplo, falar um determinado idioma ou perceber relações geométricas. A formação dessas aptidões acontece em consonância com o processo de apropriação, ou seja, de domínio, pelo indivíduo, do patrimônio cultural criado pela humanidade ao longo do processo histórico. (EIDT; DUARTE, 2007, p. 54).

Essa reflexão torna evidente o papel central da atividade para o desenvolvimento psicológico da criança. Porém, é importante esclarecer que a afirmação de que atividade da criança conduz ao desenvolvimento psicológico não se refere a qualquer atividade. A perspectiva histórico-cultural propõe que existe um tipo de atividade que provoca o desenvolvimento psicológico de maneira mais intensa nos diferentes períodos do desenvolvimento infantil a qual é denominada como atividade-guia.

Desse modo, Facci (2004) esclarece que cada estágio de desenvolvimento de toda criança envolve uma relação que se estabelece entre ela e os adultos que a inserem em atividades voltadas para satisfazer suas necessidades. A cada estágio formam-se necessidades a serem supridas, visto que a criança, ao dedicar-se às atividades-principais (ou atividade-guia) de cada período, está relacionando com o mundo de modo a produzir novas necessidades.

A autora, baseando-se em Leontiev, Elkonin e Vigotski, afirma que os principais estágios de desenvolvimento que todas passam são comunicação emocional direta, atividade objetal-manipulatória, jogo de papéis (brincadeira), atividade de estudo, comunicação íntima pessoal e atividade profissional (FACCl, 2004). Considerando-se os objetivos desse estudo, entre as atividades-guia mencionadas pela autora destaca-se a brincadeira ou jogo de papéis, cuja importância fundamenta a necessidade da brinquedoteca como espaço para a formação de pedagogos.

Para tanto, Marcolino, Barros e Mello (2014, p. 98), defendem a utilização do jogo como atividade-guia para a prática docente na Educação Infantil. Destacam que a centralidade do jogo protagonizado na infância não é o uso de objetos, mas sim as relações sociais que se estabelecem entre as pessoas e criança.

Tais relações são estabelecidas mediante ações realizadas com os objetos, em função do atendimento das necessidades da criança, e, para assimilar essas relações, as crianças imitam na brincadeira o comportamento dos adultos. Essa forma de atividade coloca a criança em um novo lugar nas relações sociais na medida que elas passam a fazer uso dos objetos simbolicamente e começam a entender os diferentes papéis sociais existentes ao reproduzi-los na brincadeira.

Dessa forma, entendendo a brincadeira como atividade-guia da idade pré-escolar as publicações foram analisadas comparativamente. As Publicações $\mathbf{1} \mathbf{e} \mathbf{2}$ apresentam algumas contribuições do teórico Vigotski nas análises, enfatizando a função do brinquedo para relação com o mundo, de forma superficial e sem abordar o conceito de brincar e o que representa para o desenvolvimento da criança.

$\mathrm{Na}$ Publicação 2 verificou-se a presença de aspectos da Psicologia Histórico-Cultural como por exemplo no trecho: "A brinquedoteca é um espaço que proporciona, por meio da atividade lúdica, tanto a construção quanto a reconstrução do conhecimento socialmente produzido e historicamente acumulado" (REIS; ARAÚJO; BATISTA, 2017, p. 102). Evidencia um aspecto importante da perspectiva histórico-cultural relacionado ao reconhecimento do caráter social e histórico da brincadeira infantil, 
entretanto, não aborda conteúdos relacionados ao papel que a brincadeira infantil cumpre no desenvolvimento psíquico da criança.

Na Publicação 1 a brincadeira e apresentada como meio pelo qual a criança revela sua visão de mundo, ao mesmo tempo em que a reformula por meio da própria brincadeira. Ressalta, também, a importância da intervenção dirigida para que a criança desenvolva sua criatividade visto que:

É fundamental que as brincadeiras ou as aprendizagens ocorram por uma intervenção direta com riqueza e diversidade de experiências para que as crianças possam exercer a capacidade de criar. A brincadeira pode se estabelecer primeiro no plano da imaginação, o que implica que aquele que brinca tenha o domínio da linguagem simbólica, também sendo necessário apropriar-se de elementos da realidade de maneira a atribuir-lhes novos significados (VIGOTSKI, 1987, p. 35 apud KOCHEM; VALENTE; MARCATO, 2018, s/p.).

Além de associar a brincadeira ao desenvolvimento da linguagem simbólica os autores da referida publicação ressaltam as capacidades psicológicas que a brincadeira requer das crianças de forma coerente com a concepção proposta pela psicologia Histórico-Cultural. Desse modo, apesar de não situar a brincadeira como atividade-guia na idade pré-escolar, é possível afirmar que a Publicação 1 é a que mais se aproxima de uma concepção Histórico-cultural com relação à função que a brincadeira exerce no desenvolvimento do psiquismo.

A Publicação 3 apresenta uma visão sobre a brincadeira como especificidade da infância, focando apenas na importância do lúdico e da brinquedoteca para os alunos de pedagogia e para as crianças que faziam usufruto do projeto.

\section{CONCLUSÃO}

Sem o intuito de esgotar a discussão proposta pelo presente artigo sobre a brinquedoteca enquanto laboratório didático na formação do pedagogo é possível fazer algumas constatações.

Sobre a brinquedoteca e as políticas públicas em educação para formação do pedagogo destaca-se que os documentos oficiais, como diretrizes curriculares e instrumentos de avaliação de curso, apresentam informações superficiais sobre a função da brinquedoteca. Para se construir uma proposta de brinquedoteca universitária, minimamente, comprometida é preciso analisar os documentos oficiais que embasam as práticas na Educação Infantil a fim de se compreender a concepção de infância.

Aliada a essa questão verificou-se a ausência de referência ou classificação dos tipos de brinquedoteca, bem como de uma concepção comum. A partir dos dados da pesquisa apresentada foi reforçada a ideia de que a relação entre brinquedoteca e formação do pedagogo ainda está em processo de construção.

Defende-se a brinquedoteca como espaço formativo em potencial dos pedagogos, que possibilita a articulação entre teoria e prática, para além de um espaço de manuseio e uso dos brinquedos em estratégias didáticas. Visto que a importância da brincadeira está no seu próprio desenvolvimento 
como atividade central no processo de formação do psiquismo infantil e não como mera ferramenta de ensino de outros conteúdos.

Como possibilidade de superação de práticas superficiais, espontaneístas e evasivas na promoção do desenvolvimento humano, seja da criança ou do futuro pedagogo, envolve o estudo e aprofundamento teórico dos autores da Psicologia Histórico-Cultural que reconhecem o papel determinante que a cultura tem na formação do ser humano.

\section{REFERÊNCIAS}

ARCE, Alessandra. O jogo e o desenvolvimento infantil na teoria da atividade e no pensamento educacional de Friedrich Froebel. Cad. CEDES, Campinas, v. 24, n. 62, p. 9-25, abr. 2004. DOI: 10.1590/S0101-32622004000100002. Disponível em http://www.scielo.br/scielo.php?script=sci_ arttext\&pid=S0101-32622004000100002\&lng=pt\&nrm=iso. Acesso em: 8 dez. 2019.

CARNEIRO, M. A. B. Brinquedoteca: um espaço interessante para favorecer o desenvolvimento da criança. 2015. http://www4.pucsp.br/educacao/brinquedoteca/downloads/brinquedoteca.pdf Acesso em: 8 dez. 2019.

EIDT, Nadia Mara; DUARTE, Newton. Contribuições da teoria da atividade para o debate sobre a natureza da atividade de ensino escolar. Psicol. educ., São Paulo, n. 24, p. 51-72, jun. 2007. Disponivel em: http://pepsic.bvsalud.org/scielo.php?script=sci_arttextapid=S1414$69752007000100005 \& l n g=p t \& n r m=i s o$. Acesso em: 8 dez. 2019.

FACCI, Marilda Gonçalves Dias. A periodização do desenvolvimento psicológico individual na perspectiva de Leontiev, Elkonin e Vigostski. Cad. CEDES, Campinas, v. 24, n. 62, p. 64-81, abr. 2004. DOI: 10.1590/S0101-32622004000100005. Disponível em <http://www.scielo.br/ scielo.php?script=sci_arttext\&pid=S0101-32622004000100005\&lng=pt\&nrm=iso >. Acesso em: 8 dez. 2019.

KISHIMOTO, T. M. Diferentes tipos de brinquedoteca. In: ANDRADE C. et al. 0 direito de brincar. São Paulo: Scritta, Abrinq, 1992.

KOCHEM, K. S. B. C.; VALENTE, F. M.; DE SOUZA MARCATO, D. C. B. A importância do projeto brinquedoteca aberta na Universidade Federal de Mato Grosso do Sul para formação pedagógica dos discentes. v. 1, n. 1. 2018. Campo Grande. Jornada Brasileira de Educação e Linguagem, 3 / Jornada de Educação do Mato Grosso do Sul/ Encontro dos Mestrados Profissionais em Educação e Letras, 12, 2018. Anais..., Campo Grande, UEMS, 2002. Disponível em: http://anaisonline.uems.br/index. php/jornadaeducacao/article/view/4875/4902. Acesso em: 8 dez. 2019. 
MARCOLINO, S.; BARROS, F. C. O. M.; MELLO, S. A. A teoria do jogo de Elkonin e a educação infantil. Psicol. Esc. Educ., Maringá, v. 18, n. 1, p. 97-104, June 2014. Disponível em: http://www. scielo.br/scielo.php?script=sci_arttext\&pid=S1413-85572014000100010\&lng=en\&nrm=iso. Acesso em: 8 dez. 2019.

MENDES, Jacqueline Araujo Corrêa et al. Brinquedoteca Universitária: espaço de formação e de experiências lúdicas. Revista Intercâmbio, v. 11, p. 187-204, 2018. http://www.intercambio. unimontes.br/index.php/intercambio/article/view/253. Acesso em: 8 dez. 2019.

MOZZATO, A. R.; GRZYBOVSKI, D. Análise de conteúdo como técnica de análise de dados qualitativos no campo da Administração: potencial e desafios. Revista de Administração Contemporânea, Curitiba, v. 15, n. 4, p. 731-747, 2011. DOI: 10.1590/S1415-65552011000400010. Disponível em: http://www.scielo.br/scielo.php?script=sci_arttext\&pid=S1415-65552011000400010\&lng=pt\&nrm= iso. Acesso em: 8 dez. 2019.

PORTO, C. L. Brinquedo e brincadeira na brinquedoteca. In: KRAMER, S.; LEITE, M. I. (Org.). Infância e produção cultural. Campinas: Papirus, 1998. p. 171-98.

REIS, F. S.; ARAÚJO, P. S. C.; BAPTISTA, T. J. R. Brinquedoteca universitária e formação de professores: [in]visibilidades acadêmicas. Dossiê Aspectos Históricos do Esporte e Lazer, Belo Horizonte, v. 3, n. 4, p.96-115, dez. 2017. Quadrimestral. Disponível em: https://seer.ufmg.br/index. php/rbel/article/view/10195. Acesso em: 8 dez. 2019.

SILVÉRIO, C. A., RUBIO, J. de A. S. Brinquedoteca hospitalar: o papel do pedagogo no desenvolvimento clínico e pedagógico de crianças hospitalizadas. Revista Eletrônica Saberes da Educação, v. 3, n. 1, 2012. Disponível em: http://docs.uninove.br/arte/fac/publicacoes/pdf/v3-n12012/Claudia.pdf. Acesso em: 8 dez. 2019. 
1 Doutora e Mestre em Psicologia Escolar e Desenvolvimento Humano - IP-USP; Graduada em Psicologia, Pedagogia e Ciências Sociais; Professora do curso de Pedagogia - UMC; Pesquisadora do Programa em Políticas Públicas - UMC. E-mail: platzer@uol.com.br

2 Doutora em Educação Escolar - UNESP; Mestra em Educação - PUCSP; Graduada em Psicologia; Professora do curso de Pedagogia - UMC. E-mail: crsilvau@gmail.com

3 Doutor em Educação Escolar (UNESP/Araraquara); Pós-doutorado em Ciências Sociais (UNESP/Marília); Professor na Universidade de Mogi das Cruzes e pesquisador em diversos institutos; Pesquisador Associado em Projetos na FAPESP. E-mail: r.silva@unesp.br

4 Pedagoga - UMC. E-mail: aninha_paulaperez@hotmail.com 5 Pedagogo - UMC. E-mail: douglas.g.prado@hotmail.com

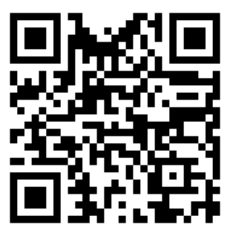

A autenticidade desse artigo pode ser conferida no site https://periodicos. set.edu.br

\section{(2) (1) (-)}

Este artigo é licenciado na modalidade acesso abertosob a Atribuição-Compartilha Igual CC BY-SA
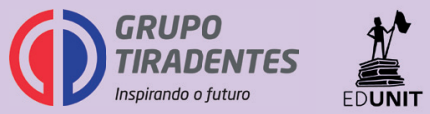
